\title{
Recent developments in solar $\mathrm{H}_{2}$ generation from water splitting
}

\author{
SIVARAMAN RAJAAMBAL ${ }^{\mathrm{a}}$, KUMARSRINIVASAN SIVARANJANI ${ }^{\mathrm{a}}$ and \\ CHINNAKONDA S GOPINATH ${ }^{\mathrm{a}, \mathrm{b}, \mathrm{c}, *}$ \\ ${ }^{a}$ Catalysis Division, National Chemical Laboratory, Dr. Homi Bhabha Road, Pune 411 008, India \\ ${ }^{\mathrm{b}}$ Centre of Excellence on Surface Science, National Chemical Laboratory, Dr. Homi Bhabha Road, \\ Pune 411 008, India \\ ${ }^{\mathrm{c} N e t w o r k}$ of Institutes for Solar Energy (NISE), NCL Campus, Pune 411 008, India \\ e-mail: cs.gopinath@ncl.res.in
}

MS received 24 July 2014; revised 21 August 2014; accepted 22 August 2014

\begin{abstract}
Hydrogen production from water and sunlight through photocatalysis could become one of the channels, in the not-so-distant future, to meet a part of ever growing energy demands. However, accomplishing solar water splitting through semiconductor particulate photocatalysis seems to be the 'Holy Grail' problem of science. In the present mini-review, some of the critical strategies of semiconductor photocatalysis are focused with the aim of enumerating underlying critical factors such as visible light harvesting, charge carrier separation, conduction and their utilization that determine the quantum efficiency. We attempted to bring out the essential requirements expected in a material for facile water splitting by explaining important and new designs contributed in the last decade. The newly emerged designs in semiconductor architecture employing nanoscience towards meeting the critical factors of facile photocatalysis are elucidated. The importance of band gap engineering is emphasized to utilize potential wide band gap semiconductors. Assistance of metal nanostructures and quantum dots to semiconductors attains vital importance as they are exuberant visible light harvesters and charge carrier amplifiers. Benevolent use of quantum dots in solar water splitting and photoelectrochemical water splitting provides scope to revolutionize the quantum efficiency by its multiple exciton generation features. A list of drawbacks and issues that hamper the much needed breakthrough in photocatalysis of water splitting is provided to invite attention to address them and move towards sustainable water splitting.
\end{abstract}

Keywords. Semiconductor; quantum dot; water splitting; hydrogen; nanomaterial; photocatalysis; visible light.

\section{Introduction}

Increasing energy demand drives the global research community in search of alternative sustainable resources and processes. Currently, the world energy supply relies on fossil fuels as one of the principal energy sources, which are getting depleted rapidly. Expected production of conventional fuels was elucidated by Hubbert curve, indicating the peak of oil production to be hit first in this decade followed by the peak of coal supply. ${ }^{1}$ However, the production will become scarce around middle of this century and the problem is further intensified by the growing world population. Additionally, global warming is another threat caused by $\mathrm{CO}_{2}$ emission from fossil fuel combustion. These lead to a conclusion that renewable resources are earnestly and urgently needed for the global community.

\footnotetext{
*For correspondence
}

Solar energy utilization seems to be possible along with lucrative solution to resolve our energy and environment issues. The sunlight that reaches the earth in a day is equivalent to hundreds of trillion barrels of oil. Simple calculation ${ }^{2}$ exemplifies that less than $0.01 \%$ conversion of sunlight is sufficient to generate required electricity, as well as fuels, like hydrogen and organic chemicals. The highest heat density of hydrogen (41 $\mathrm{kJ} / \mathrm{mol}$ ) makes it an attractive and clean fuel for fuel cells and fuel cell powered car engines, and thus its production from abundantly available water and sunlight is the cost effective approach. Hydrogen production from water mimics natural photosynthesis that produces carbohydrate. Nonetheless, the mechanistic aspects of water splitting is elucidated as an uphill reaction with high positive free energy $(237 \mathrm{~kJ} / \mathrm{mol}){ }^{3}$ Hence the rate determining $\mathrm{O}_{2}$ production step of water splitting process underscores severe thermodynamical constraints along with kinetic restraint in the breaking of the first $\mathrm{O}-\mathrm{H}$ bond, since it requires $495 \mathrm{~kJ} / \mathrm{mol}^{3}{ }^{3}$ To overcome these rigorous constraints, photo-functionally active 


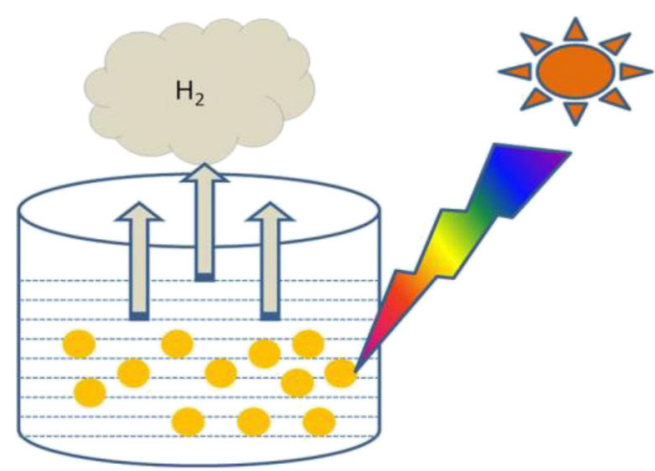

Figure 1. Schematic representation on heterogeneous semiconductor (solid yellow circles) photocatalytic water splitting under direct sunlight.

catalyst is certainly needed for lowering the activation energy barriers. Advancements in heterogeneous and homogeneous catalytic processes produce several materials for the purpose of $\mathrm{H}_{2}$ production by water splitting. Figure 1 illustrates the simplest desired way to produce hydrogen by suspended particulate photocatalyst in water under sunlight. Heterogeneous particulate photocatalysts examined in the last one decade is the scope of the present review. Although there are few other reviews available, ${ }^{4-6}$ in the present review we highlight the changes in the electronic structure due to doping of oxides, and bring out significant number of unsolved limitations that hamper the growth of this field. We also do not present the conventional aspects of water splitting, which is extensively addressed in earlier reviews. ${ }^{4-6}$

\section{Principles of photocatalysis}

Heterogeneous particulate photocatalysis is a viable process, but achieving considerable efficiencies remains the biggest challenge for the last four decades, since the discovery of water splitting was announced by Fujishima and Honda. ${ }^{7}$ To accomplish decent efficiency with sustainability is the most essential part, and towards that it is essential to scrutinize the basic processes involved in water splitting.

\subsection{Basic processes}

There are three important steps involved in semiconductor photocatalysis: (a) Photon absorption: Semiconductor photocatalyst material absorbs photon having energy greater than its band gap. Absorbed photon is utilized to excite an electron from the valence band (VB) of semiconductor to the conduction band (CB) and forms a free exciton $\left(\mathrm{e}^{-}-\mathrm{h}^{+}\right)$pair. (b) Second step involves charge carrier separation into the constituent species (electrons and holes), and their migration to the surface, where the redox reactions should occur. These are the two critical factors in deciding the efficiency of the process because recombination of excited electron and hole pair can occur in femtoseconds in bulk. Electron migration from bulk to surface without being quenched is assisted by electronic structure of semiconductor and co-catalyst, particle size, crystallinity and other morphological factors in providing appropriate diffusion length of charge carriers. ${ }^{5}$ (c) Surface chemical redox reactions is the final step in which charge carriers are utilized for the desired purpose, such as the conversion of water molecules into hydrogen and oxygen. Potentials of CB-minimum $\left(\mathrm{CB}_{\min }\right)$ should be more negative than hydrogen reduction $\left(2 \mathrm{H}^{+}+2 \mathrm{e}^{-} \rightarrow \mathrm{H}_{2}\right)$ potential; in contrast, VBmaximum $\left(\mathrm{VB}_{\max }\right)$ should be more positive than 1.23 $\mathrm{eV}$ at normal hydrogen electrode (NHE) scale for effecting oxidation. Band structure of the semiconductor should go hand in hand in deciding light absorption and redox potentials of photogenerated electron and hole. ${ }^{8}$ Semiconductor possessing $\mathrm{CB}_{\min }>0 \mathrm{eV}$ vs NHE scale cannot reduce water to evolve hydrogen. For example, $\mathrm{WO}_{3}$ can absorb visible light, but its $\mathrm{CB}_{\text {min }}$ potential is positive and restricted to evolve oxygen alone. Various semiconductor band edge potentials at NHE scale is shown in figure 2. Most wide band gap semiconductors are able to provide suitable redox potential for water splitting reaction. However, to work under sunlight, semiconductors necessarily have to absorb significant to entire range of visible light (400-700 nm). On the whole, critical factors can be summarized as follows: a) visible light absorption, b) charge carrier separation and migration to surfaces, and c) charge carrier utilization. The detailed explanation is furnished in the flow chart shown in figure 3. Besides these factors, photo- and hydro-stability of the

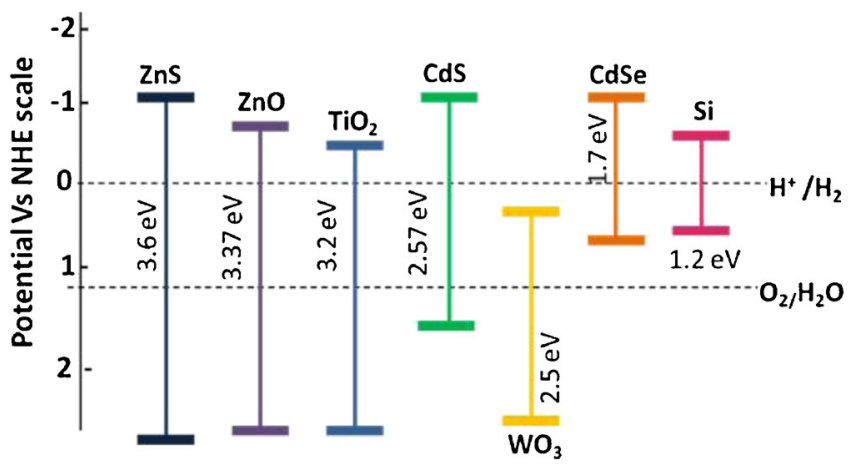

Figure 2. Band gap potential diagram of semiconductors at normal hydrogen electrode (NHE) scale. 


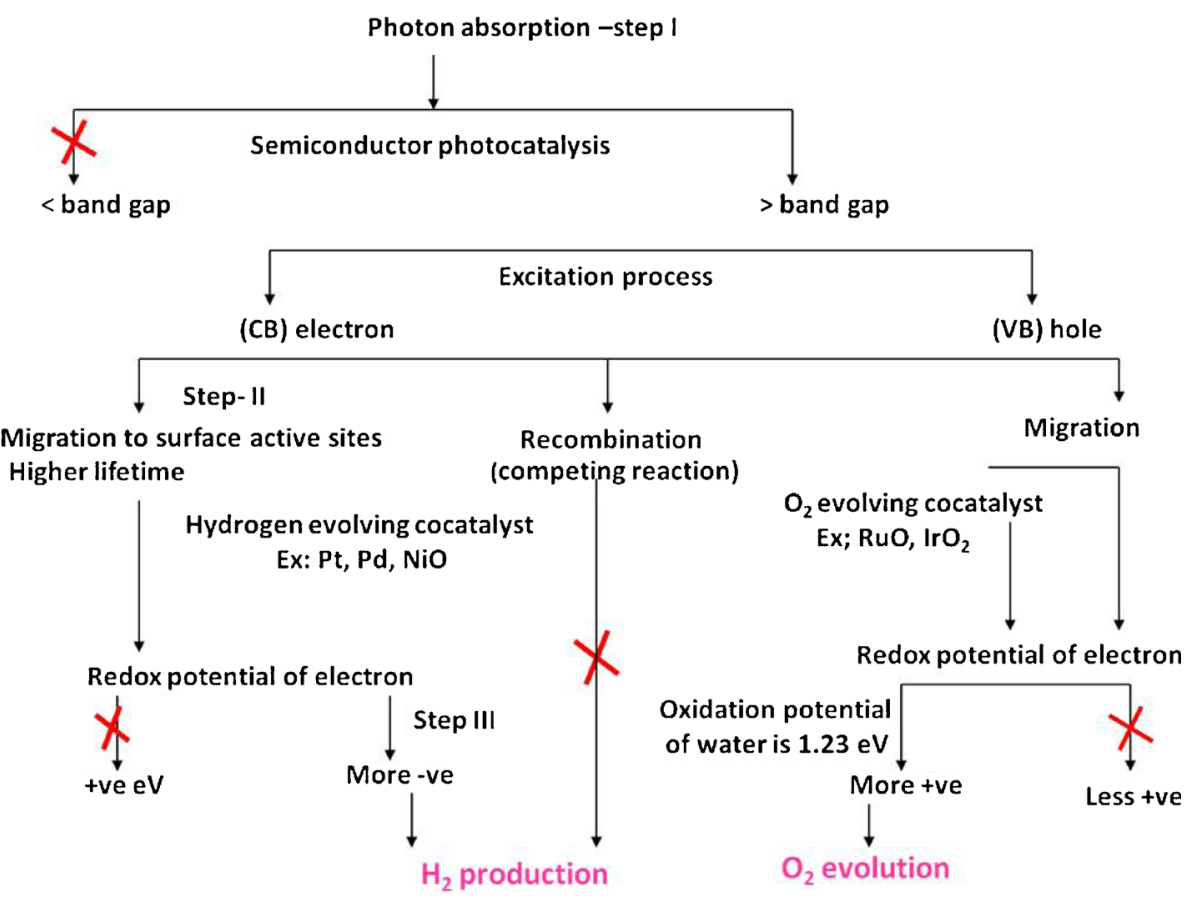

Figure 3. Flowchart representation of the basic and critical processes involved in heterogeneous semiconductor photocatalysis.

photocatalyst is another major issue for sustainable $\mathrm{H}_{2}$ production, for which photocorrosion of metal ions from oxide has to be avoided.

\subsection{Use of sacrificial agents}

Charge recombination is the fastest fundamental process, which limits the efficiency of any photocatalysis reaction. Sacrificial agents are being used with the purpose of enhanced utilization of one of the charge carrier for attaining improved efficiencies; in this process charge recombination is also minimized. Sacrificial agents act as either hole or electron scavengers for hydrogen or oxygen evolution, respectively. Hole scavenging sacrificial agents, such as methanol, abstracts hole and gets oxidized to $\mathrm{CO}_{2}$, through sequential steps. ${ }^{3}$ Due to this process, the electron excited to $\mathrm{CB}$ exhibits higher lifetime and they are better utilized for reduction. On the other hand, electron scavenging reagent, such as silver nitrate, acts exactly in the opposite manner to the above hole scavenger and holes are utilized for oxidation. As the hole scavengers are more favourably oxidized, due to lower oxidation potential than water molecules, the thermodynamical and kinetic constraints are greatly reduced. It is to be underscored that water splitting is an uphill reaction with a free energy change $(\Delta \mathrm{G})=237 \mathrm{~kJ} / \mathrm{mol}^{3}{ }^{3} \Delta \mathrm{G}$ decreases significantly as it avoids four electron process of molecular oxygen formation. Decrease in $\Delta \mathrm{G}$ is dependent on several factors, such as nature of sacrificial agents, its oxidation/reduction potential. Replacement of methanol by bio-friendly alcohols, like glycerol and carbohydrates, are also suggested with the concern on environmental issues. ${ }^{3}$ Use of glycerol is advantageous from higher hydrogen content per molecule aspect, though carbon to hydrogen ratio is lesser than methanol. Nonetheless, $\mathrm{H}_{2}$ production through water splitting reaction (WSR) with a sacrificial agent, such as methanol, glycerol, might be considered as a short term goal, as it is relatively less difficult than overall water splitting reaction (OWSR) without any sacrificial agent. ${ }^{9}$ In our opinion, OWSR could be considered as a long term solution for energy demands, given the rate of progress of OWSR for the last three decades.

\subsection{Z-Scheme photocatalysis}

Inspired by nature, two photon artificial photocatalysis system has been developed through which harvesting rate of useful photons can be doubled. Two different catalysts having different specific potential to $\mathrm{H}_{2}$ and $\mathrm{O}_{2}$ evolution are utilized, mediating through a redox couple which has been illustrated in figure 4. Bard et al introduced this methodology which is the mimic of $\mathrm{Z}$-scheme operating for electron relay in natural photosynthesis. ${ }^{10}$ 


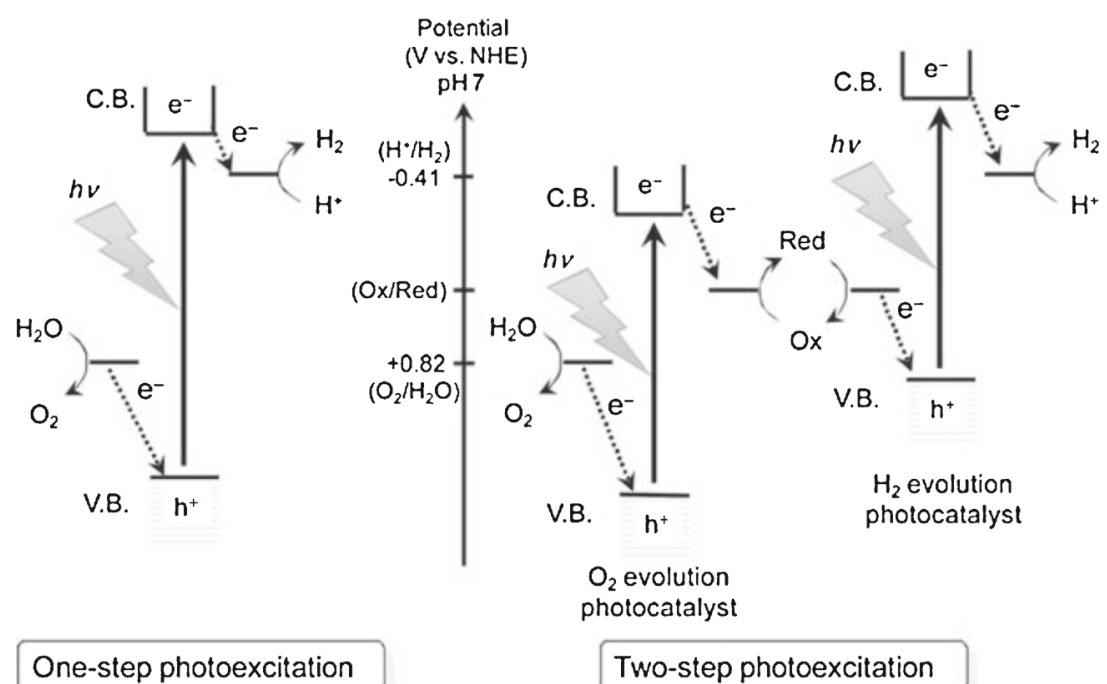

Figure 4. Schematic representation of one-step and two-step photoexcitation processes. (Reproduced with permission from ACS).

Two-step photocatalytic system is advantageous over single photocatalysis system in the aspects of separated $\mathrm{H}_{2}$ and $\mathrm{O}_{2}$ evolution and thermodynamically favourable half-reaction mechanistic approach. As high quantum yields can be expected by half reactions, research interest has been directed on the development of different combinations of photocatalysts with and without electron mediators. ${ }^{11,12}$ Metal oxide semiconductors whose band gap potential is attenuated to do either oxidation or reduction can be exploited for their catalytic excellence. Owing to better visible light absorption of oxynitrides, than oxides, Domen et $a l^{13}$ explored Pt loaded modified $\mathrm{TaON} / \mathrm{ZrO}_{2}$ and $\mathrm{Pt} / \mathrm{WO}_{3}$ composite. This material shows 'non-sacrificial' hydrogen evolution with $6.3 \%$ quantum yield at a wavelength of $420.5 \mathrm{~nm}$. As $\mathrm{Z}$ scheme photocatalysis is being 'non-sacrificial' in principle it has laid strong scope on developing eco-friendly hydrogen generation systems. It is also to be mentioned that on doubling the catalyst weight, quantum yield decreases to about $2.7 \%$ with $\mathrm{Pt} / \mathrm{TaON} / \mathrm{ZrO}_{2} / \mathrm{WO}_{3} .{ }^{13}$ Indeed, light scattering, rather than absorption, increases with increasing amount of photocatalytic material is a persistent problem, which tremendously decreases the efficiency of any photocatalytic systems. This aspect is untouched by (m)any group(s) and must be addressed while scaling up WSR. Although, in our opinion, the time is not ripe for this, since solar light driven and sustainable photocatalyst with more than $10 \%$ efficiency for WSR is yet to be discovered, which is likely to be a breakthrough; nevertheless, it is worth exploring this aspect.

\section{Semiconductors}

\subsection{Doped semiconductors}

Semiconductors are generally considered to be suitable materials for photocatalysis. Unfortunately semiconductors such as $\mathrm{TiO}_{2}, \mathrm{ZnO}$, absorb UV light due to band gap higher than $3.1 \mathrm{eV}$, and they are not active in the visible light. On the other hand, those semiconductors that absorb visible light, such as $\mathrm{CdS}, \mathrm{CdSe}, \mathrm{WO}_{3}$, are vulnerable to photocorrosion; further, band egde potential doesn't match to the requirement of water splitting. Suitable doping of such photocatalyst is required to engineer the band gap to the desired value. One of the important strategies to develop visible light active photocatalyst is to dope either metal ion or non-metal ion into the bulk of semiconductor materials.

3.1a Metal ion (cation) doping: Metal ion doping in the semiconductor produces localized energy levels in the forbidden gap (between $\mathrm{CB}$ and $\mathrm{VB}$ ) of a given semiconductor material. Figure 5 illustrates a schematic representation of donor level (above the VB), and acceptor level (below the $\mathrm{CB}$ ) produced by doped metal ion impurities. The electron transfer from these new energy levels to $\mathrm{CB}$ allows this wide band gap semiconductor material to absorb radiations in the visible light region. $\mathrm{TiO}_{2}, \mathrm{SrTiO}_{3}, \mathrm{ZnS}$, layered perovskites are some of the popular UV-active photocatalytic materials used for WSR. Anpo et al doped many metal ions, that are listed in periodic table, into $\mathrm{TiO}_{2}$ by high energy ion implantation technique and showed the shift 


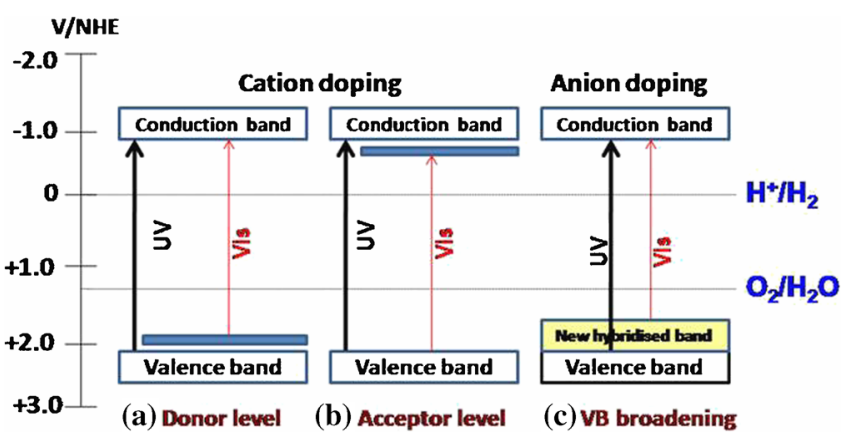

Figure 5. Schematic representation of the formation of (a) new donor, and (b) acceptor levels by cation doping, and (c) band broadening of valence band by anion doping.

of absorption edge into visible light region. ${ }^{14,15}$ Above red shift depends on the type and concentration of the doped metal ions. In all metal-ion doped semiconductors, a new donor level is created above the VB of titania and the transition from this new donor level to $\mathrm{CB}$ of titania occurs with low energy (visible light) photons. In most of the cases, though these doped metal ions increase the visible light absorption, they act as recombination centres which reduce the photocatalytic activity of bulk semiconductor materials. $\mathrm{TiO}_{2}$ doped with either $\mathrm{Cr}^{3+}, \mathrm{Ni}^{2+}$ or $\mathrm{Rh}^{3+}$ alone shows no activity for WSR. This is primarily due to the charge imbalance caused by these dopant metal ions which increase the defect sites and hence they are detrimental to photocatalytic activity. This problem is solved partially by co-doping these ions with other metal ions ${ }^{16,17}$ such as $\mathrm{Ta}^{5+}, \mathrm{Nb}^{5+}$ or $\mathrm{Sb}^{5+}$. Ru doped $\mathrm{TiO}_{2}{ }^{18}, \mathrm{Pt}$, Ir, and $\mathrm{Co}$ doped $\mathrm{TiO}_{2}$ nanotubes, ${ }^{19} \mathrm{Cr}^{3+} / \mathrm{Ta}^{5+}-$ and $\mathrm{Cr}^{3+} / \mathrm{Sb}^{5+}$ codoped $\mathrm{SrTiO}_{3}$ is active visible light photocatalyst for WSR. Researchers reported the $\mathrm{Cr}, \mathrm{Fe}$ doped $\mathrm{La}_{2} \mathrm{Ti}_{2} \mathrm{O}_{7}$ layered material for hydrogen evolution reaction under visible light irradiation. Zou et $a l^{20}$ doped many metal ions in $\mathrm{InTaO}_{4}$, among them $\mathrm{In}_{0.9} \mathrm{Ni}_{0.1} \mathrm{TaO}_{4}$ shows stoichiometric evolution of $\mathrm{H}_{2}$ and $\mathrm{O}_{2}$ under visible light irradiation. $\mathrm{Ni}$ and $\mathrm{Cu}$-doped $\mathrm{ZnS}$ show good activity towards $\mathrm{H}_{2}$ evolution reaction with sacrificial $\mathrm{K}_{2} \mathrm{SO}_{3}$ and $\mathrm{Na}_{2} \mathrm{~S}$ solution. However, mainly due to photocorrosion problems, many of the above metal ion doped semiconductors disintegrate under photocatalysis reaction conditions.

3.1b Non-metal ion (anion) doping: Unlike metal ions, the possibility of energy state overlap of doped non-metal ion (anions) with that of VB states of the semiconductor oxide (O 2p) material is high, since the energy spread of anions is generally high. Due to this energy overlap either the VB is shifted upward or it broadens the VB thus reducing the overall band gap.
This concept is illustrated in figure 5c. Asahi et $a l^{21}$ prepared $\mathrm{N}$-doped $\mathrm{TiO}_{2}$ and proposed that anions such as $\mathrm{C}, \mathrm{N}, \mathrm{F}, \mathrm{P}$ or $\mathrm{S}$ doping in $\mathrm{TiO}_{2}$ could alter the electronic states of $\mathrm{TiO}_{2}$. However, among all anions, nitrogen doping led to promising results because $\mathrm{N} 2 \mathrm{p}$ states overlap with that of $\mathrm{O} 2 \mathrm{p}$ and reduces the band gap efficiently. $\mathrm{S}$ doping shows similar band gap narrowing but due to its large ionic radius it is difficult to incorporate significant amount of $\mathrm{S}$ in $\mathrm{TiO}_{2}$ lattice. C and $\mathrm{P}$ doping lead to new energy state that occur deep into the forbidden gap (or mid-gap state), which act as a recombination centre. Moreover in semiconductor oxide material, $\mathrm{N}$ can be incorporated in substitutional or in interstitial position. Among them, substitutional $\mathrm{N}$ decreases the band gap more efficiently than interstitial nitrogen. Satish et $a l^{22}$ showed a definite band gap reduction by $0.13 \mathrm{eV}$ due to nitride-like nitrogen doping in $\mathrm{N}-\mathrm{TiO}_{2}$ and supported by XPS, visible light absorption and photocatalytic acivity in visible light. Domen $e a^{23}$ have prepared many solid solutions, such as $\mathrm{ZnO}$ in $\mathrm{GaN}$ (table 1), by using conventional nitridation technique, which requires ammonia treatment for many hours at $800-900{ }^{\circ} \mathrm{C}$. Alternatively, Mapa et $a l^{24}$ prepared $\mathrm{N}$ doped $\mathrm{ZnO}$ by using simple solution combustion method (SCM) from zinc nitrate and urea, and requires lower temperature $\left(500^{\circ} \mathrm{C}\right)$. Moreover $\mathrm{SCM}$ is very rapid and up to 15 atom\% $\mathrm{N}$ can be incorporated into $\mathrm{ZnO}$. $\mathrm{N}$-doping in the bulk of metal oxide lattice involves metal-oxygen (M-O) bond breaking followed by $\mathrm{M}-\mathrm{N}$ bond formation by conventional nitridation. However, metal-oxo nanoclusters with plenty of oxygen defects were grown in in-situ generated ammonia atmosphere facilitates the $\mathrm{N}$-doping in oxide. SCM method was successfully employed to introduce $\mathrm{N}$ in $\mathrm{ZnO}$ and $\mathrm{TiO}_{2}{ }^{8,24-26}$ Nishijima et $a l^{27}$ have prepared $\mathrm{S}$ doped $\mathrm{TiO}_{2}$ and showed its WSR activity under visible light. Moreover $\mathrm{C}$ doped $\mathrm{TiO}_{2}$ with rutile structure shows better activity than pure titania with mixed phases. Recently there are many reports available for the co-doping of two or more anions. ${ }^{4} \mathrm{~F} / \mathrm{B}, \mathrm{F} / \mathrm{N}, \mathrm{F} / \mathrm{S}$, $\mathrm{F} / \mathrm{C}, \mathrm{S} / \mathrm{N}, \mathrm{C} / \mathrm{N}, \mathrm{Cl} / \mathrm{Br}, \mathrm{N} / \mathrm{S}$ and $\mathrm{B} / \mathrm{N}$ are doped in $\mathrm{TiO}_{2}$ which increases the visible light absorption and showed higher activity for hydrogen evolution for WSR. Especially in $\mathrm{B} / \mathrm{N}$ doped $\mathrm{TiO}_{2}, \mathrm{~B}$ acts as shallow traps ${ }^{28}$ for electrons which will reduce the recombination probability. $\mathrm{N}$ doping in $\mathrm{Ta}_{2} \mathrm{O}_{5}$ also shows similar effect as that of $\mathrm{TiO}_{2}$.

\subsection{Oxynitrides and oxysulphides}

An idea of doping of anions, such as nitride, sulphide, in oxides gives rise to a new class of materials called oxynitride and oxysulphide, which exhibit better visible 
Table 1. Important examples of semiconductor material designs for solar water splitting.

\begin{tabular}{|c|c|c|c|}
\hline Photocatalysts & Highlight feature of the working system & $\mathrm{H}_{2} \mu \mathrm{mol} / \mathrm{h}^{-1}$ & Ref \\
\hline $\mathrm{TiO}_{2}: \mathrm{Cr}$ & Doping imparts visible light absorption & 268 & 17 \\
\hline $\mathrm{N}$ doped $\mathrm{Zn}-\mathrm{Ga}$ mixed oxide & Oxynitride system with suppressed defect densities & 37202 & 64 \\
\hline $\mathrm{Ga}_{0.88} \mathrm{Zn}_{0.12} \mathrm{~N}_{0.88} \mathrm{O}_{0.12}$ & Solid solution Evolves hydrogen in stiochiometric ratio & 2800 & 32 \\
\hline $\mathrm{Cu}_{0.25} \mathrm{Ag}_{0.25} \operatorname{In}_{0.5} \mathrm{ZnS}_{2}$ & $\begin{array}{l}\text { Sulphide based solid solution with enhanced visible light } \\
\text { absorption showing tenability with respect to composition }\end{array}$ & 7666 & 65 \\
\hline $\mathrm{ZnS}-\mathrm{In}_{2} \mathrm{~S}_{3}-\mathrm{CuS}$ & Composite with visible light absorption & 410688 & 66 \\
\hline $\mathrm{ZnFe}_{2} \mathrm{O}_{4} / \mathrm{SrTiO}_{3}$ & $\begin{array}{l}\text { Composite with layered structure providing separate active } \\
\text { sites for } \mathrm{H}_{2} \text { and } \mathrm{O}_{2} \text { evolution }\end{array}$ & 360000 & 67 \\
\hline $\mathrm{CdSe} / \mathrm{CdS}$ & Composite with matching band alignment & 40000 & 38 \\
\hline MWCNT/Dye & $\begin{array}{l}\text { Porous and charge transporting structure for increasing } \\
\text { charge carrier mobility }\end{array}$ & 3060 & 42 \\
\hline $\mathrm{TiO}_{2}$-long nanotubes & $\begin{array}{l}\text { Composite for combing light harvesting and charge } \\
\text { carrier transporting properties }\end{array}$ & 4690 & 68 \\
\hline $\mathrm{TiO}_{2}-\mathrm{NT} / \mathrm{CuO}$ & Composite exhibiting nanosize effects & 100000 & 71 \\
\hline $\mathrm{TiO}_{2} / \mathrm{Au}$ & $\begin{array}{l}\text { Electronically integrated composite combining SPR effects } \\
\text { of Au and porosity for charge carrier utilization }\end{array}$ & 1500 & 9 \\
\hline $\mathrm{TiO}_{2}$ Nanowire $/ \mathrm{Au}$ & $\begin{array}{l}\text { Combination of charge carrier transport and SPR } \\
\text { effects of noble metal Au nanoparticle and nanorods }\end{array}$ & $1.5 \mathrm{mAcm}^{-1}$ & 70 \\
\hline CdS-ZnS: Ag & Sulphide composite sensitized by SPR of Ag nanoparticle & 40975.5 & 56 \\
\hline CdS QD: $\mathrm{Zn}_{1-x} \mathrm{Cd}_{\mathrm{x}} \mathrm{S}$ & Quantum dot sensitized solid solution & 2500 & 64 \\
\hline $\mathrm{N}: \mathrm{TiO}_{2} / \mathrm{CdSe}$ & Synergistic effect of $\mathrm{N}$ doping and QD sensitization & $0.35 \mathrm{~mA} / \mathrm{cm}^{2}$ & 63 \\
\hline $\mathrm{TiO}_{2} \mathrm{Nanotubes}_{3} 3 \mathrm{~nm}$ size $\mathrm{CdSe}$ & Quantum dot sensitization and charge transport & $2.5 \mathrm{mAcm}^{-1}$ & 69 \\
\hline
\end{tabular}

light absorption compared to oxides. Energy overlapping of $N 2 p$ or S $3 p$ bands with that of O $2 p$ VB leads to VB broadening and thereby narrowing the optical band gap of the material. ${ }^{8}$ This can be achieved possibly in many types of oxides belonging to different crystal structures. Visible light harvesting was achieved by anion doping and demonstrated through WSR or photocurrent generation, indicating the dopant increases photon to current or chemical conversion. However, poor nitrogen solubility seems to be one of the possible reasons for instability of oxynitrides. With conventional high temperature nitridation method of $\mathrm{N}$-doping, a maximum of 3 atom $\% \mathrm{~N}$-doping could be achieved. ${ }^{29}$

Another aspect of increasing nitrogen content is codoping with suitable metal ions. Group III metal ions show strong affinity toward nitrogen and their respective nitrides are extensively studied for their brilliant emission properties. Some of these metal nitrides (GaN) are UV active and there are also demonstrations on them for water splitting. When these metal-ions are co-doped in desired oxide they enrich nitrogen content yielding oxynitrides. They are advantageous over respective oxides and nitrides for hydrogen evolution. ${ }^{30}$

Generally sulphide compounds have inherent visible light absorption. Therefore visible light absorption through sulphur doping in oxides was expected. Ogisu et $a l^{31}$ have synthesized a series of lanthanum based oxysulphides demonstrating broad visible light absorption around $630 \mathrm{~nm}$. On the contrary preferential photooxidation of sulphide anions causes leaching of the material under irradiation conditions. Above undesired leaching can be tackled by combining both wide band gap and narrow band gap material through solid solutions or core-shell morphological structures.

\subsection{Solid solution}

Solid solution is a homogenous crystal structure formed by two or more compounds that share same crystal lattice. They provide new dimension of band gap engineering in oxides. In oxysulphides and oxynitrides, defect densities are comparatively less due to high degree of lattice match between the integral units of structure. Wide band gap semiconductors are UV active, on the other hand, narrow band gap semiconductors do not have sufficient potentials for water splitting. When solid solution formed between two wide band gap semiconductors, band structure is altered in such a way that it can absorb visible light and split water. This illustrates the indispensability of solid solutions for band gap engineering in figure 6 .

Solid solutions of oxides and nitrides are of great interest as they exhibit distinguished photophysical properties from that of oxides and nitrides. Band structure of the solid solutions can be tuned over compositions also. However the range of compositions is limited by the solubility and necessary band edge factors. $\mathrm{GaN}: \mathrm{ZnO}$ solid solution is a typical example (table 1) 


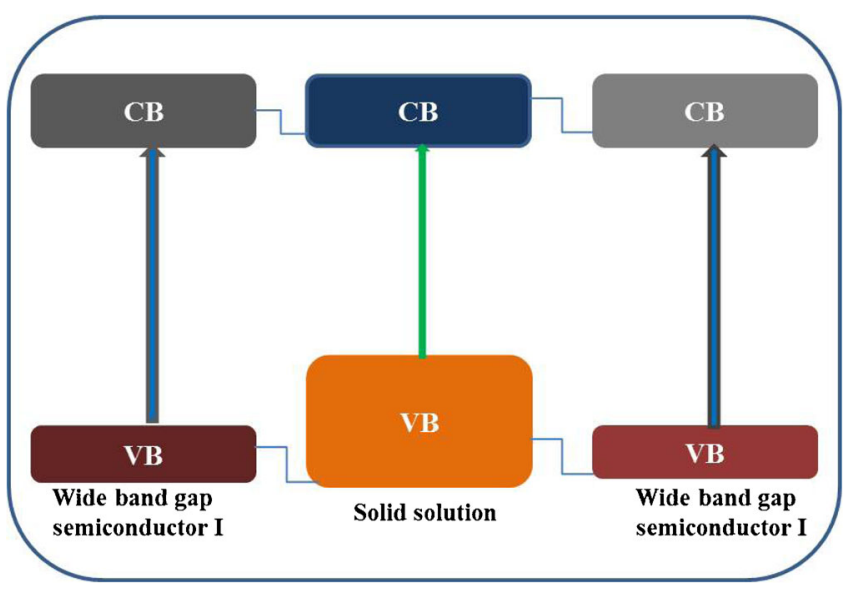

Figure 6. Band gap engineering of solid solutions towards lower band gap and visible light absorption.

among oxynitride solid solutions prepared by Maeda et $a l^{32}$ through conventional nitridation method, and Mapa $e t a l^{33,34}$ by SCM. The new observation is that solid solution shows visible light absorption onset around $550 \mathrm{~nm}$, though individual $\mathrm{GaN}$ and $\mathrm{ZnO}$ components are limited to UV absorption only. Visible light absorption is achieved in the solid solution due to the energy overlap of $\mathrm{N} 2 \mathrm{p}$ bands with that of $\mathrm{O} 2 \mathrm{p}$ resulting in optical band gap reduction to around $2.2 \mathrm{eV}$.

Sulphide solid solutions are developed with the interest of achieving maximum visible light harvesting. Further, photocorrosion has also been overcome by structure stability of solid solution. CdS, a well-studied photocatalyst is combined with $\mathrm{ZnS}$ semiconductor in a core-shell structure to attain photostability. Notably $\mathrm{Cd}_{1-x} \mathrm{Zn}_{x} \mathrm{~S}(x-0.2)$ solid solution does not require noble metal loading to perform WSR in visible light and also highly active for hydrogen evolution with quantum efficiency of $10.2 \%$ at $420 \mathrm{~nm} .{ }^{35}$ Several groups focused on silver based oxysulphide solid solutions for its inherent visible light absorption. It is increasingly evident that many sulphide solid solutions perform WSR without any co-catalyst or noble metal loading underscoring its high potential associated with them. Various examples for these classes of materials can be found in the literature reports. ${ }^{5,6,8}$

\subsection{Composites}

Electronic coupling of two different semiconductors is one of the important ways to utilize the charge carriers effectively by reducing recombination probabilities. Visible light absorption can be enhanced by coupling small band gap semiconductor with that of large band gap. ${ }^{36}$ On 1984, Serpone et al ${ }^{37}$ demonstrated that the interparticle electron tranfer from the
CB of CdS to $\mathrm{TiO}_{2}$, and utilized the same to demonstrate $\mathrm{H}_{2}$ production by $\mathrm{H}_{2} \mathrm{~S}$ decomposition under visible light. $\mathrm{CdS} / \mathrm{ZnO}, \mathrm{CdS} / \mathrm{ZnS}, \mathrm{CdS} / \mathrm{KNbO}_{4}$ are some of the important composites with CdS because of exhibiting good activity towards visible light driven hydrogen generation (table 1). ${ }^{38}$ In single phase oxide system, the rate of charge carrrier recombination is more. This rate can be minimized by coupling two semiconductors with proper ohmic contact. In this coupled system, band edge offset between the individual semiconductors gives the potential for the transportation of photo excited charges along a preferential route which improves the seperation of photo excited electrons and holes. $\mathrm{TiO}_{2} / \mathrm{SnO}_{2}$, $\mathrm{Cr}$ doped $\mathrm{Ba}_{2} \mathrm{In}_{2} \mathrm{O}_{5} / \mathrm{In}_{2} \mathrm{O}_{3}, \mathrm{In}_{2} \mathrm{~S}_{3} / \mathrm{Pt}-\mathrm{TiO}_{2}$ are some of the important composites which shows good activity towards WSR under visible light. ${ }^{39,40}$

Recently many worthwhile efforts have been made to make composites with carbon based materials. Chai et $a l^{41}$ reported highly active multi-walled carbon nano tube (MWCNT) with $\mathrm{ZnIn}_{2} \mathrm{~S}_{4}$ as a composite system for $\mathrm{H}_{2}$ production under visible light. MWCNT provides a convenient way to direct the flow of photogenerated charge carriers. So these type of composites increase the lifetime of charge carriers generated under irradiation. ${ }^{42} \mathrm{CdS} /$ graphene, $\mathrm{C}_{3} \mathrm{~N}_{4}$ /graphene, CdS/MWCNT, N-Sr $\mathrm{Ta}_{2} \mathrm{O}_{4}$ /graphene, $\mathrm{TiO}_{2} /$ reduced graphene oxide (RGO), $\mathrm{WO}_{3} /$ graphene are some of the important composites prepared recently, and these composite materials shows high activity towards WSR under visible light. ${ }^{43,44}$ In all these composites, graphene played a role similar to MWCNT, thus increasing the photocatalytic activity of these materials.

\subsection{Porous materials}

Porous materials received significant attention from photocatalysis researchers. They have many advantages and are regularly used as catalytic materials due to high surface area, less diffusional barriers for reactants and products, compared to highly crystalline and bulk materials. High surface area will give more number of reactive sites as well as it helps us to harvest the maximum light energy. Leaf structure in plants is a typical example for porous strcuture for efficient light harvesting. Though charge carriers form on light absorption, the chances of charge recombination in the bulk is high, since the distance from the bulk to the reaction centres on the surface is greater than the electron diffusion length. Figure 7 shows a schematic representation of the difference between bulk and porous materials. Among the ordered regular and disordered porous materials, the latter have an advantage of short 


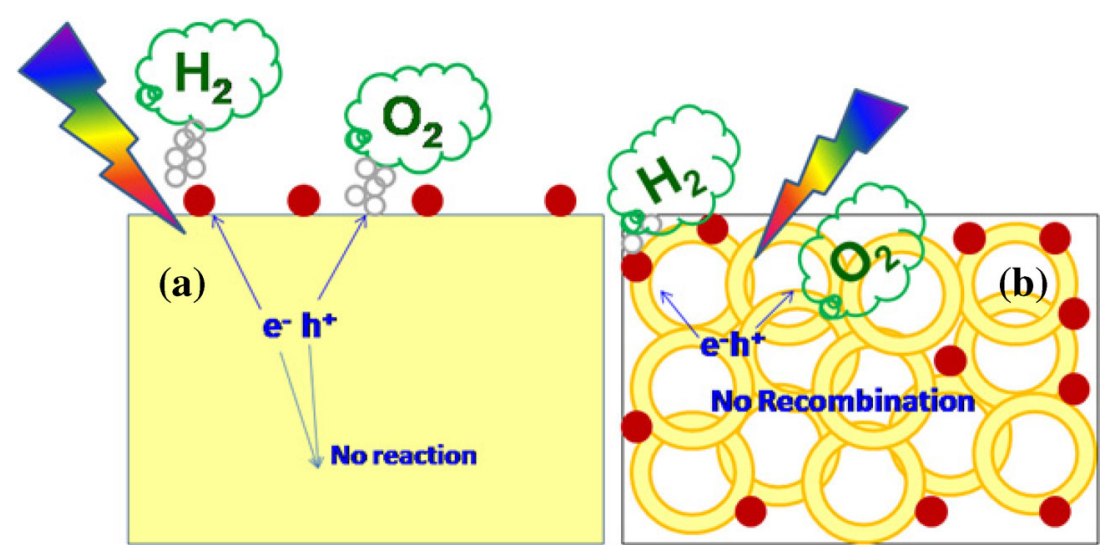

Figure 7. Schematic representation of photocatalytic water splitting on (a) bulk photocatalyst, and (b) mesoporous photocatalyst.

diffusion length for reactants/products. ${ }^{45}$ Indeed, rate of recombination of charge carriers is significantly reduced, especially with disordered porous materials. There are many reports available for the preparation of mesoporous $\mathrm{TiO}_{2}$ and these mesoporous $\mathrm{TiO}_{2}$ shows better photocatalytic activity than bulk $\mathrm{TiO}_{2}$. Sivaranjani et $a l^{50,51}$ recently reported template free synthesis of disordered $\mathrm{N}$-doped $\mathrm{TiO}_{2}$ by SCM. Materials mentioned above possess all the positive aspects required for better photocatalytic activity, such as high surface area, electrically interconnected nano crystalline particles and low diffusion barriers. Indeed the low diffusion barrier is attributed to the disordered mesoporosity, which leads to very small meso channel depth and hence exhibits psuedo 3D ( $p 3 \mathrm{D})$ character. This is in contrast to the conventional ordered mesoporous materials, such as SBA- $15 .{ }^{46}$ This disordered p3D $\mathrm{TiO}_{2-x} \mathrm{~N}_{\mathrm{x}}$ shows good photocatalytic and photovoltaic properties compared to commercial $\mathrm{TiO}_{2}$. Mesoporous $\mathrm{SrTiO}_{3}, \mathrm{Nb}_{2} \mathrm{O}_{5}$ and $\mathrm{InVO}_{4}$ gives better photocatalytic activity than its bulk counterpart. Recently Zhang et $a l^{47}$ reported on $\mathrm{CuS} / \mathrm{ZnS}$ porous nanosheets preparation by hydrothermal method. CuS/ZnS exhibits high rate of $\mathrm{H}_{2}$ production with QE of $20 \%$ at $420 \mathrm{~nm}$ without using any co-catalyst. Porous structure is believed to facilitate the transportation of reactants and products through the interior space due to the interconnected porous network and to increases the light harvesting by multiple scattering within the porous framework and somewhat similar to natural leaf structure. Bao et $a l^{48}$ have prepared nanoporous CdS and demonstrated its high activity towards WSR with a QE of $60 \%$ at $420 \mathrm{~nm}$.

\section{Metal nanostructures for solar water splitting}

There are many efforts devoted in the last decade in demonstrating photocatalysis by plasmonic nanostructure of noble metals, particularly gold and silver, loaded on semiconductors. Nanometer sized noble metals, transition metals and their respective oxide clusters are extensively explored as sensitizers and/or co-catalyst to take advantage of their visible light absorption by surface plasmon resonance (SPR) and hydrogen evolving features.

\subsection{Plasmonic nanostructures for water splitting}

Plasmonic metal nanostructure loaded semiconductor has been explored to a great extent from the age of Fujishima and Honda's first demonstration on semiconductor photoelectrochemical water splitting in the context of co-catalyst. ${ }^{49}$ Plasmonic metal nanostructures strongly interact with UV or visible light photons through a phenomenon called SPR. A collective oscillation of CB electrons leads to light absorption in noble metal nanoclusters. SPR frequency is different for different metals according to their electronic structure. For example, gold, silver and copper nanostructures exhibit resonance in visible region, whereas $\mathrm{Pb}, \mathrm{In}, \mathrm{Hg}, \mathrm{Sn}$ and Cd exhibit resonance in UV region. ${ }^{50}$ The resonating wavelength and SPR intensity depends on the size and shape of nanoparticles, and composition.

4.1a Plasmonic nanostructures as visible light harvesters: Plasmonic-metal nanostructures possess up to three order of magnitude higher visible light absorption cross-section, scattering power, tunable visible light absorption to a significant extent, and enhanced stability compared with typical organic dyes. ${ }^{49,50}$ They provide high photon penetration depths effecting greater interaction with the material that amplifies charge carrier generation; this aspect is advantageous over semiconductors, which lack strong interaction with photon due to low penetration depths. 
Nanostructures loaded on semiconductors boosts incoming flux intensity which is directly proportional to the generation of charge carriers and hence $\mathrm{QE}$ is expected to be high. Large porous nanostructures $(>50$ $\mathrm{nm}$ ) influence scattering of absorbed light, which allows several passes of photons into the material resulting in increased flux absorption through internal reflection. This is similar to photosynthesis, in which scattering within the leaf microstructure takes center stage in light harvesting. Nanostructures with high scattering coefficient underscore good visible light absorption at high wavelengths. These exuberant light harvesting features identify plasmonic-metal nanostructures as antennas for wide band gap semiconductors for visible light absorption. Among metals, Au, Ag, Pt received attention on par of its nobility and visible light SPR. The shapes of those plasmonic nanostructures implicate serious consideration on light harvesting. Generally cube shaped nanoparticles show more absorption in visible region on account of two times greater extinction coefficient than that of spherical and rod shapes. ${ }^{51}$ Rod shapes for $\mathrm{Au}$ nanostructures received attention for its additional absorption maximum at its longer axis and size tunability owing to greater aspect ratio that is lacking in the case of spherical shapes. Sivaranjani et al prepared electronically integrated $\mathrm{Au} / \mathrm{TiO}_{2-x} \mathrm{~N}_{\mathrm{x}}$ mesoporous nanocomposites that show good activity for solar hydrogen generation. Disordered porous structure assists in easy charge carrier diffusion from bulk to surface of the active sites and SPR effect of Au nanoparticles enable visible light activity (table 1$).{ }^{9}$

\section{1b Plasmonic nanostructures as charge carrier} utilizers: Plasmonic nanostructures can build up strong intense localized field. Enhancement of electric field intensity is observed between $10^{3}$ to $10^{6}$ times stronger than incident photon flux..$^{9,43}$ These spots are often called hot spots which are responsible for generating HOT electrons. The enhancement of field intensity depends on the nature of metal. Nanostructures are attached to semiconductors either through nonconductive linkers or directly. Semiconductor surface can interact with electric field intensity in the vicinity of optimized $5 \mathrm{~nm}$ distance from nanoparticle and generate charge carriers localized on its surface. ${ }^{52}$ Semiconductor surfaces which interact with hot spots produce higher rate of charge carriers. In the case of direct contact, loss of charge carriers occur in the form of heat, known as Frostier resonance energy transfer (FRET). Due to above direct contact there will be distribution of photogenerated electron on both of them. Since quantum size effect results electron confinement in smallest size $(<3 \mathrm{~nm})$ particles their band levels tend to be flat and no space charge layer is formed. Under light irradiation photogenerated electrons accumulate and raise the Fermi level $\left(E_{F}\right)$ of the composite, wherein $E_{F}$ of metal and semiconductor is in equilibrium. ${ }^{9,53} \mathrm{As}_{\mathrm{F}}$ of the composite become more negative the free energy of reduction capacity also turns to be more negative influencing enhanced water reduction. There will be facile charge separation in the nanostructure loaded semiconductor composite system because charge carrier is selectively generated at three-phase boundary formed by semiconductor, metal nanostructure and aqueous medium. The three-phase boundary is being the reaction site in WSR and thus, recombination is highly suppressed in that site.

\section{1c Photocatalysis on plasmonic metal nanostructures:}

Plasmonic-metal nanostructure loaded semiconductor composites exhibit higher catalytic yield compared to bare semiconductor. This concept is demonstrated by photocurrent generation studies from the observation that visible light driven current generation is several times higher for composites than simple metal oxides. Figure 8 shows comparative photocurrent study for $\mathrm{TiO}_{2}$ and $\mathrm{Au} / \mathrm{TiO}_{2}$ at high wave length $(\lambda=633 \mathrm{~nm})$, where titania don't exhibit any absorption. ${ }^{54}$ Although the magnitude of the current produced is low, it is exclusively attributed to the intense local field produced at Au-sites due to SPR. This is further supported by photoluminescence studies in which emission is observed at the wavelength corresponding to SPR. Moreover, catalytic studies clearly demonstrate the enhancement of catalytic yield for composite compared to semiconductor, and the maximum yield for composite is achieved at its SPR wavelength. Figure 8 also shows that $\mathrm{Au}$ loaded $\mathrm{TiO}_{2}$ have higher performance than $\mathrm{TiO}_{2} \cdot{ }^{54}$ It was suggested that enhancement can occur feasibly when there is resonance between the energy of metal SPR and absorption of semiconductor.

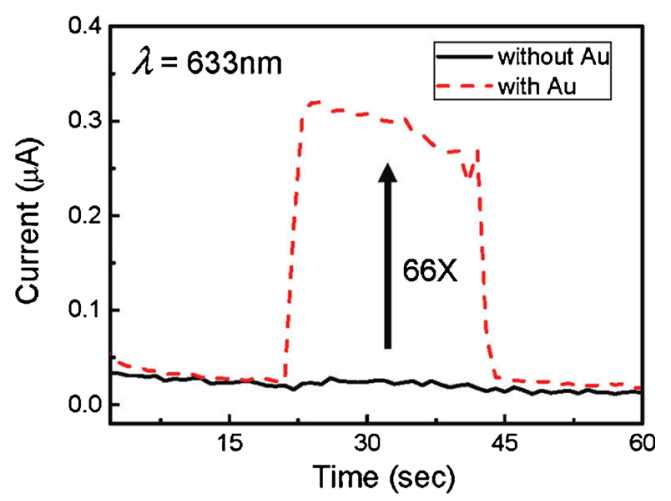

Figure 8. Photocurrent of $\mathrm{TiO}_{2}$ with and without $\mathrm{Au}$ nanoparticles irradiated at $\lambda=633 \mathrm{~nm}$ light. (Reproduced with permission from ACS). 
4.1d Function of co-catalyst: Till date co-catalyst are inevitable to semiconductors for considerable hydrogen production. Role of co-catalyst mainly focuses on QE determining factors, such as charge separation and surface chemical reactions. Co-catalysts are categorized as, a) noble metal co-catalyst, b) transition metal oxide co-catalyst, and c) non-oxide cocatalyst. Co-catalyst loaded on semiconductor surface acts as sink for photogenerated charge carriers. Thus the availability of charge carriers on surface facilitates surface chemical reactions by suppressing recombination of photogenerated charge carriers. Since the $E_{F}$ of noble metal is lower than that of semiconductor, electron transfer from $\mathrm{CB}$ of semiconductor is facilitated to noble metal. Composite of $\mathrm{CdS}$ : $\mathrm{ZnS} / \mathrm{Au}$ shows several times higher activity than the composite without noble metal loading. Additional advantage is the provision of specific active sites with low activation energy barriers for $\mathrm{H}_{2}$ evolution. ${ }^{55,56}$ To achieve high yield of $\mathrm{H}_{2}$ and $\mathrm{O}_{2}$, two different co-catalysts are employed. They form separate active sites for $\mathrm{H}_{2}$ and $\mathrm{O}_{2}$ evolution and arrest back reaction. The schematic illustration of the role of co-catalyst is shown in figure 9.

\section{Quantum dots for solar water splitting}

In recent years quantum dots (QD) have drawn new genre of attention as vital building blocks of third generation photovoltaic devices. QDs are semiconductor nanoparticles whose electronic motions are confined in all the three dimensions of space. The strong electron confinement influences quantization in energy levels analogous to discrete atoms. The quantized energy levels facilitate the modulation of electronic properties thereby offering special advantages in promoting light harvesting and charge carrier utilization. QDs of cadmium chalcogenides, like $\mathrm{CdSe}, \mathrm{CdTe}, \mathrm{CdS}, \mathrm{PbS}$, and III-V semiconductors like InAs, GaAs, InP are significantly studied in photovoltaic devices as sensitizers to

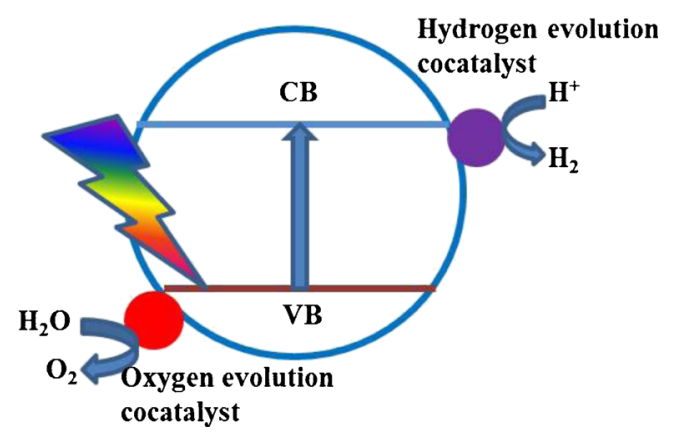

Figure 9. Role of two different metal nanostructures as cocatalyst for hydrogen and oxygen evolution. wide band gap semiconductors like $\mathrm{TiO}_{2}, \mathrm{ZnO}, \mathrm{SnO}_{2}$. Importance of QDs in water splitting is discussed in the following section.

\subsection{Semiconductor quantum dots as visible light harvesters}

QDs possess high visible light absorption coefficients and enriched stability that enable the use of QD in lieu of costly noble metal containing photoactive dyes. Bulk semiconductor has low capacity to interact with photons, whereas small quantity of QDs of semiconductor can able to harvest the maximum flux of photons as it strongly interacts with photons due to quantum size effect. The key advantage of size quantization property borne by QD is tuneablity of optical band gap with respect to size, shape and composition which opens up ways in building up of multi-gap systems to cover the entire range of solar spectrum. ${ }^{57}$ Figure 10 depicts the modulation of optical band gap by controlling the size of CdSe QD and different colours associated with them. When the size of QD decreases the band gap increases significantly, and as a consequence the colour of the QD varies from red to violet on decreasing the size. In addition to shifts in optical absorption, the energetics favouring for electron transfer from $\mathrm{CB}$ of QD to the $\mathrm{CB}$ of semiconductor can also be modulated in such a way to attain thermodynamically feasible electron or hole transfer, particularly to large band gap semiconductors. As the size of the QDs decreases the CB edge shifts to more negative potential. This in turn decreases the free energy change i.e., $-\delta \mathrm{G}$ for electron transfer from QD to semiconductor. It is supported by the kinetic studies that electron transfer rate constant for smaller

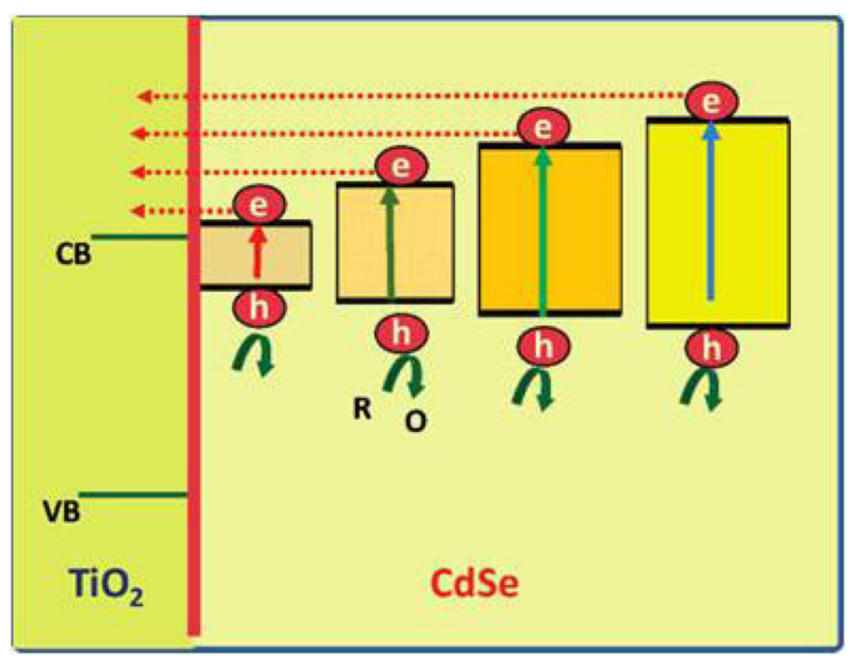

Figure 10. Size quantization in CdSe QDs of varying size and the direct electron transfer from CdSe to $\mathrm{CB}$ of $\mathrm{TiO}_{2}$. (Reproduced with permission from ACS publication). 
QD is higher than larger QD. This imparts that small QD can transfer electron at fast rate.

Rajaambal et al prepared structurally and electronically integrated $\mathrm{InGaN}$ quantum dot in $\mathrm{ZnO}$ matrix (InGaN@ZnO) through viable solution combustion method. ${ }^{58}$ The solid state integration brings the visible light harvesting component by $\mathrm{InGaN}$ and fast electron transport component through $\mathrm{ZnO}$ in vicinity with each other. Synchronous activity by both the above component separate the charge carriers, to avoid/minimize recombination, and hence an increase in activity in visible light. Large reduction in optical band gap to 1.8$1.9 \mathrm{eV}$ was observed with InGaN@ZnO, compared to $3.37 \mathrm{eV}$ for $\mathrm{ZnO}$. Reduction in band gap was attributed to broadening of VB due to energy overlap of $\mathrm{N} 2 \mathrm{p}$ (nitride) states of InGaN with that of $\mathrm{O} 2 \mathrm{p}$ states from $\mathrm{ZnO}$ and hence the VB was shifted towards Fermi level. This is advantageous for enhancing incident photon to conversion efficiencies because of simultaneous conversion of light energy into electrical energy. ${ }^{58}$ High photocurrent generated in visible light at an applied voltage of $0 \mathrm{~V}$ underscores the importance InGaN@ZnO (figure 11) for many optoelectronic application. In

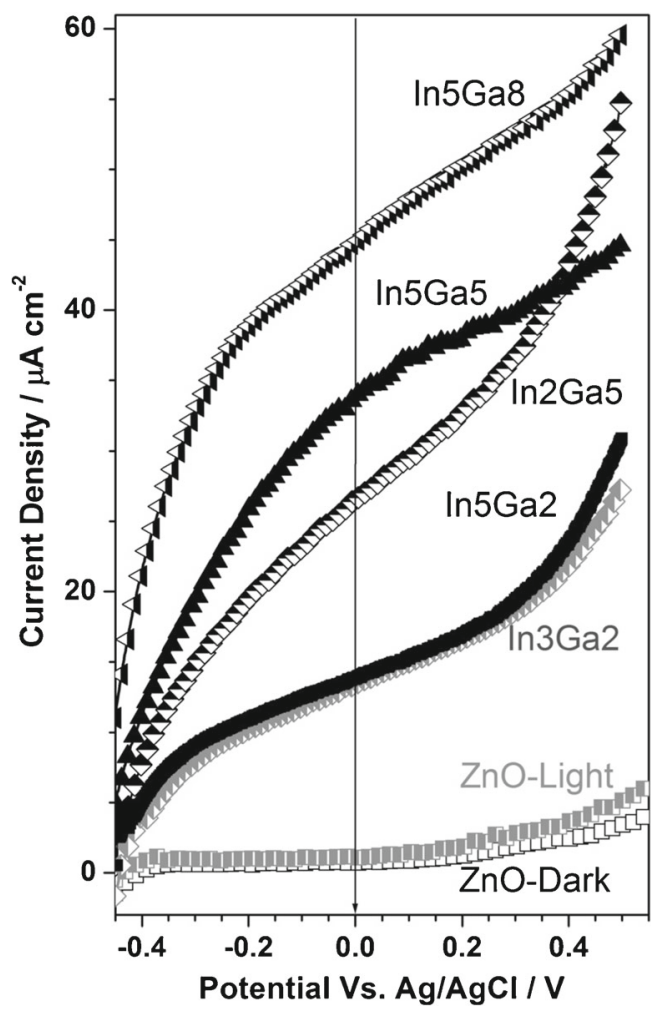

Figure 11. Linear sweep voltammograms of InGaN@ZnO and $\mathrm{ZnO}$ under $20 \mathrm{~mW} / \mathrm{cm}^{2}$ irradiation with visible band pass filter $(\lambda=380-770 \mathrm{~nm})$. Number followed by In and $\mathrm{Ga}$ in the material code indicate the atom percent of In and Ga, respectively, for InGaN@ZnO. Solid line underscores the photocurrent generated at zero applied voltage. addition, InGaN@ZnO also shows overall water splitting without any sacrificial agent in visible light. Further, solid state integration of quantum dots in bulk of host matrix is evident from the above work, which is the first of its kind. It is to be noted that quantum dots are normally prepared by colloidal methods and hence its integration with solid is a perennial problem.

\subsection{Quantum dots for charge carrier utilization}

Recently QDs are remarkably noted for featuring multiple exciton generation, a process by which an absorbed photon generates multiple excitons. ${ }^{59}$ Theoretically, this can yield over $100 \%$ QE surpassing the energy conversion efficiency of traditional Shockley and Queisser limit of $32 \%$ for Si based solar cells. Additionally this multiple exciton generation process could generate hot electrons that can amplify the incoming photon fluxes. Thus there are significant chances to increase QE by employing QDs.

The next advantage provided by QDs is charge separation, which is a critical requirement to suppress competing charge recombination process. Especially this is important when the size of QDs falls below the range of excitonic Bohr radius. As the charge carrier diffusion lengths are smaller than Bohr radius there will be facile charge carrier separation. In addition to the above, by coupling QD with wide band gap semiconductors, rate of transfer of charge carriers is increased. Strong carrier localization exhibited by QDs can prevent trapping of charge carriers in defects as non-radiative recombination centres. These advantages furnished by QDs for visible light absorption and charge carrier utilization makes them potential candidates for solar water splitting.

To circumnavigate the deleterious aggregation QDs, they need to be capped by ligands (or spacers) in the colloidal dispersions. The ligands stabilizing the QDs also serve as linkers for their attachment to semiconductors. However the capping agents have to be chosen correctly to keep quenching effects of ligands and solvents at bay. Detailed description on the synthetic aspects can be found in literature. ${ }^{60}$ In some occasions ligands are removed by chemical bath deposition method in order to bring direct contact with semiconductors. However passivation of surface defects is unavoidable. It is possible to overcome these adversities by introducing suitable changes in the preparation methods.

\subsection{Photocatalytic applications}

Photocatalysis of QD sensitized semiconductors (QDSS) is promoted by interfacial charge transfer from 


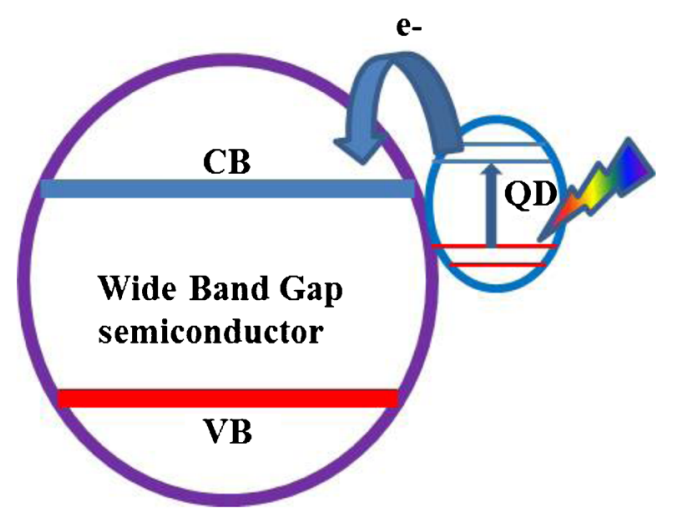

Figure 12. QD sensitized photocatalysis: Visible light absorption and charge carrier generation by QD and electron transfer to semiconductor.

QDs to semiconductor at the heterojunction formed between them. Figure 12 shows a schematic representation of visible light absorption by QD and transfers electron to semiconductor through heterojunctions. This is very similar to dye-sensitized solar cell (DSSC) concept. As QDs can harvest visible light there is good photon conversion efficiency achieved even at high wavelengths. Photocatalytic studies using the above principle are increasingly adopted by several groups. At present QDSS systems as photoelectrode attract much attention in photoelectro-chemical hydrogen evolution.

Chen et $a l^{61}$ first demonstrated photoelctrochemical water splitting by $\mathrm{CdTe}$ sensitized $\mathrm{ZnO}$ nanowire arrays in non-sacrificial electrolyte under visible light. Photocurrent density for CdTe QDs loaded $\mathrm{ZnO}$ is three times higher than that of $\mathrm{ZnO}$ alone, indicating the importance of QDs in harvesting visible light. A sharp increase in the interfacial charge transfer from CdTe to $\mathrm{ZnO}$ paves way to achieve higher QE than $\mathrm{ZnO}$ nanowires. CdS/CdSe QDs co-sensitized mesoporous $\mathrm{TiO}_{2}$ photoelectrode shows very good hydrogen production due to cascade electronic structure obtained for $\mathrm{TiO}_{2} / \mathrm{CdS} / \mathrm{CdSe}$ assembly by Lee et $a l .{ }^{62}$ A stepwise structure, as shown in figure $13 \mathrm{a}$, is proposed by downward and upward shifts in the band edges due to $\mathrm{E}_{\mathrm{F}}$ alignment between $\mathrm{CdS}$ and CdSe. This induces fast charge transfer across heterojunctions thereby facilitating high hydrogen production $(220 \mu \mathrm{mol} / \mathrm{h})$ from water splitting. Hensel et al ${ }^{63}$ first demonstrated synergistic effect of nitrogen doping in $\mathrm{TiO}_{2}$ and CdSe QDs sensitization for photoelctrochemical hydrogen production under visible light. IPCE result enumerates the significance of $\mathrm{CdSe} / \mathrm{N}-\mathrm{TiO}_{2}$ (figure 13b) in solar harvesting. Conversion efficiency for $\mathrm{CdSe} / \mathrm{N}-\mathrm{TiO}_{2}$ is higher than $\mathrm{TiO}_{2}$ and $\mathrm{CdSe}-\mathrm{TiO}_{2}$.

Although the reports on QDSS photocatalytic WSR are very much limited, it is worth mentioning an important report. Yu et $a l^{64}$ reported CdS QD sensitized $\mathrm{Zn}_{1-\mathrm{x}} \mathrm{Cd}_{\mathrm{x}} \mathrm{S}$ solid solution synthesized simply by cation exchange and hydrothermal method for visible light photocatalytic $\mathrm{H}_{2}$ production $(2 \mathrm{mmol} / \mathrm{h} \mathrm{g}$ ) using $\mathrm{Na}_{2} \mathrm{~S}$ and $\mathrm{Na}_{2} \mathrm{SO}_{3}$ as sacrificial agents. In this case, CdS QDs are in direct contact with solid solutions whereby adverse effects of protecting ligands are completely eliminated. Due to quantum confinement effect of QDs, they possess more negative CB minimum energy than solid solutions that can able to induce facile charge transfer from QDs to solid solutions and then to reactants.

The rate determining step of WSR is $\mathrm{O}_{2}$ evolution process, which involves four electron transfer. This greatly demands the generation of multiple excitons per photon absorption to achieve high QE. Apparently, QD is the most suitable candidate to satisfy that condition which brings scope for its exploration at larger extent for solar water splitting in near future.
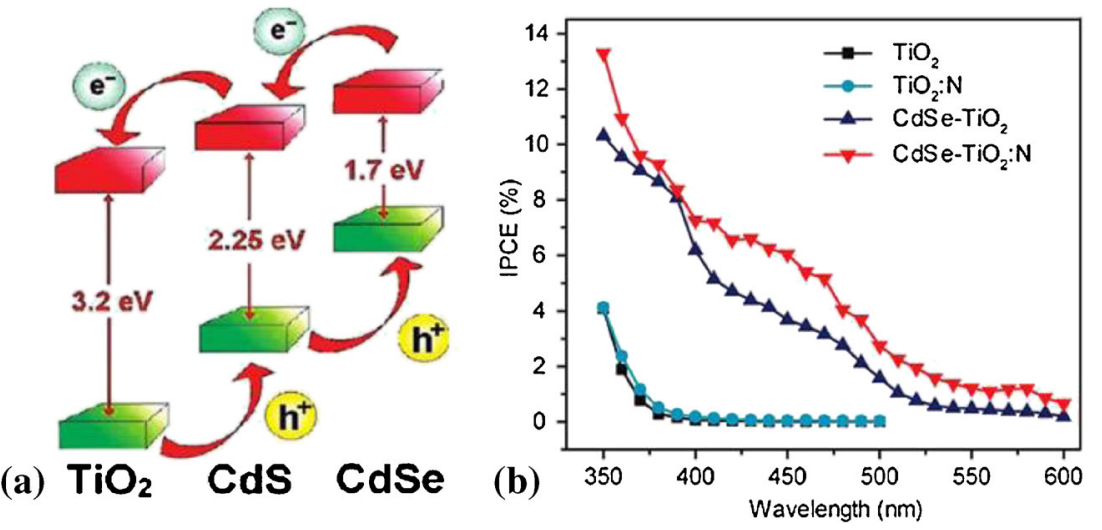

Figure 13. (a) Stepwise band structure relationship in $\mathrm{CdS} / \mathrm{CdSe}$ cosensitized $\mathrm{TiO}_{2}$. (b) IPCE for CdSe QD sensitized $\mathrm{TiO}_{2}$ and $\mathrm{N}$-doped $\mathrm{TiO}_{2}$. (Reproduced with permission from ACS publication). 


\section{Unsolved limitations}

Table 1 lists some of the recent WSR activity reported in the literature and it is evident that very high activity, such as $\mathrm{H}_{2}$ production in the range of sub-moles (0.1-0.45 moles), ${ }^{42,65,66}$ is also possible. However, in our opinion, caution is required since the reproducibility aspects of WSR is an important issue. Many a times, reported results are not reproduced in other laboratories, and there could be number of reasons for that. In our opinion, there are many critical issues that are not addressed and understood sufficiently, and in a hurry to develop highly active catalysts many issues are sidelined. It is highly important to address limiting factors prevailing in the current methodologies of photocatalysis so as to obtain desirable photoconversion efficiencies. Here we list out the critical drawbacks and some of them are entangled, which need immediate attention. (1) Multi-photon absorption systems and multielectron generating system should be considered seriously to overcome rate determining step. (2) Till date there is no precise understanding on the choice of a particular co-catalyst to a semiconductor; only very rare cases have been addressed. ${ }^{5}$ (3) Without any cocatalyst, oxide based catalysts show negligible activity. Exploration towards increasing the lifetime of photogenerated charge carriers in oxide based catalyst have to be made. Integration with suitable conducting materials, like RGO, can also help. (4) Sulphide based photocatalysts could work without co-catalyst, but persistent photocorrosion cause poor sustainability. (5) Costly noble metals are in regular use as cocatalyst and in spite of that there is no great enhancement in WSR activity. They should be replaced by cheap and efficient $3 d$ metal nanostructures. (6) Use of sacrificial agents, like methanol, has to be replaced by eco-friendly and abundantly available agents like glycerol and carbohydrates. Utilization of sacrificial agents in water splitting can be a short term solution. Overall water splitting without sacrificial agents needs to be addressed seriously and consistently. (7) To date cadmium based QD are extensively explored. Replacement of hazardous cadmium chalcogenide by eco-friendl materials are to be explored. (8) In general, QE of most of the photocatalyst decreases when scaling up the reaction even at laboratory level. For instance, results reported for $20 \mathrm{mg}$ photocatalyst need not scale up linearly to $100 \mathrm{mg}$ to few grams, ${ }^{71}$ although many researchers simply multiply the results and reports the yield. (9) In overall, water splitting evolution of hydrogen and oxygen in the stoichiometric ratio of $2: 1$ is highly difficult at $\mathrm{pH}=7$. For achieving overall water splitting, $\mathrm{pH}$ is altered to acidic regime by addition of acids which will be corrosive over a period of time. The personal commentary by Ohtani in 2008 brings out the most common problems encountered in publications pertaining to photocatalysis and we strongly recommend this article for serious photocatalysis researchers to refer to. ${ }^{72,73}$

\section{Summary and Outlook}

Present review tries to enumerate the efforts carried out in the area of photocatalysis, especially in the last one decade. It also brings out the essential requisites for photocatalysis in parallel to the limitations hindering the quantum efficiency. Several unexplored limitations are critically discussed for consideration in future efforts. Role of doping and its development to oxynitrides are outlined and further solid solution materials are noted for controlling band structure. Increasing nitrogen content in oxide matrix can bring stability to the system as well as valence band broadening for good visible light absorption. Solution combustion route is referred for its versatility as well as to increase the nitrogen content by nitrogen doping and also in forming homogenous solid solutions or quantum dots such as $\mathrm{GaN}$, InN or InGaN in $\mathrm{ZnO}$. Comprehensive note on composites and utility of disordered porous structures, resembling that of leaf microstructure, have been furnished.

Visible light absorption of metal nanostructures is emphasized, apart from its co-catalyst role. Metal nanonostructures that are loaded on semiconductors amplify the photon absorption properties of semiconductor that in turn enhances the rate of hydrogen generation particularly at SPR wavelength. Strong emphasis is given for the advent of QDs and its vitality in perspectives of mechanistic features of solar water splitting. Being multi-electron generation system, it can meet the requirements of critical rate determining step of water splitting. New and favourable methods to circumnavigate the multi-electron demanding rate determining step are discussed. The essentiality of QD for photon harvesting and energy transfer in recent years is highlighted in the review. Currently, quantum dots are explored for photoelectrochemical studies rather than direct photocatalysis. However, there is a wide scope available in future for quantum dots in solar water splitting. In conclusion, dedicated research efforts are to be devoted for efficient photon harvesting, multi-electron generation, and decreasing charge carrier recombination probability to enhance quantum efficiencies.

Although the announcement of water splitting by photoelectrochemical means was reported by Fujishima and Honda on $1972,{ }^{7}$ more than four decades have 
passed and no breakthrough has been reported for visible light-driven water splitting with sustainable efficiency around $10 \%$. This underscores the gravity of the problem. In our opinion, multipronged approach is essential to address the WSR, as it requires many factors, such as absorption of entire visible light as well as NIR, charge separation and its utilization, high lifetime of charge carriers, to be present simultaneously in one material. Integration of different components that help the above factors into one composite material or developing materials that have all the required functionalities to achieve better efficiency are the possible approaches. We also want to underscore a fact that the natural plant system works at about $1 \%$ quantum efficiency, in spite of excellent and complicated nanoarchitecture present in the leaf system for light harvesting. Probably it is time to introspect, and vertical thinking is highly required.

In our opinion, high emphasis should be given to understand the mechanistic aspects of water splitting on the surface of the photocatalyst or any solar harvesting material. So far, very limited progress has been made in the fundamental studies of water splitting. It is partly due to the large complexity involved in the photocatalysis process itself. In situ studies on the catalyst under light irradiation in the presence of water or water vapour should be measured to understand the physical, electronic and chemical changes. Recently introduced nearambient pressure photoelectron spectroscopy,${ }^{74,75} \mathrm{x}$-ray absorption, XRD and IR techniques will provide many required details. Molecular modelling of the catalyst surface could assist the above investigations.

Although visible light absorption by many solar harvesting materials/molecules is known, the second step of charge carrier separation and diffusion to the active sites is the most critical problem. Bulk crystalline materials are unlikely to help to solve the above issue; however nanocrystalline and crystalline quantum dot materials will be of immense help. High lifetime of charge carriers in the order of nanosecond to microseconds (or even higher time) is expected to improve the efficiency to a very good extent. Hence, investigations in this direction are suggested to improve the overall efficiency. The solar harvesting materials that show high lifetime of charge carriers are very likely to demonstrate high efficiency. In this regard, graphene based or singlelayered materials are likely to be potential materials for solar harvesting.

\section{Acknowledgements}

SR and KS thank CSIR, New Delhi for research fellowship. We gratefully acknowledge the funding received from TAPSUN program under NWP0056 project and MNRE supported project (GAP 296526).

\section{References}

1. King Hubbert M 1949 Science 109103

2. Kamat P V 2007 J. Phys. Chem. C 1112834

3. Bowker M 2011 Green Chem. 132235

4. Chen X, Shen S, Guo L and Mao S S 2010 Chem. Rev. 1106503

5. Kudo A and Miseki Y 2009 Chem. Soc. Rev. 38253

6. Kubacha A, Garia M F and Colon G 2012 Chem. Rev. 1121555

7. Fujishima A and Honda K 1972 Nature 23837

8. Mapa M, RajaAmbal S and Gopinath C S 2013 Trans. Mater. Res. Soc. Jpn. 38145

9. Sivaranjani K, RajaAmbal S, Das T, Roy K, Bhattacharyya S and Gopinath C S 2014 ChemCatChem 6522

10. Bard A J 1979 J. Photochem. 1059

11. Sayama K, Abe R, Arakawa H and Sugihara H 2006 Catal. Commun. 796

12. Higashi M, Abe R, Takata T and Domen K 2009 Chem. Mater. 211543

13. Maeda K, Higashi M, Lu D, Abe R and Domen K 2010 J. Am. Chem. Soc. 1325858

14. Anpo M and Takeuchi M 2003 J. Catal. 216505

15. Kato H and Kudo A 2002 J. Phys. Chem. B 1065029

16. Ohno $\mathrm{T}$, Tanigawa $\mathrm{F}$, Fujihara $\mathrm{K}$, Izumi $\mathrm{S}$ and Matsumura M 1999 J. Photochem. Photobiol. A 127107

17. Borgarello E, Kiwi J, Grätzel M, Pelizzetti E and Visca M 1982 J. Am. Chem. Soc. 1042996

18. Khan M, Akhtar A, Woo M S and Yang S I 2008 Catal. Commun. 101

19. Hwang D W, Kim H G, Lee J S, Li W and Oh S H 2005 J. Phys. Chem. B 1092093

20. Zou Z, Ye Sayama J K and Arakawa H 2001 Nature 414 625

21. Asahi R, Morikawa T,Ohwaki T, Aoki K and Taga Y 2001 Science 293269

22. Satish M B, Viswanathan R P, Viswanath B V and Gopinath C S 2005 Chem. Mater. 176349

23. Maeda K, Teramura K, Lu D, Takata T, Saito N, Inoue Y and Domen K 2006 Nature 440295

24. Mapa M and Gopinath C S 2009 Chem. Mater 21351

25. Sivaranjani K and Gopinath C S 2011 J. Mater. Chem. 212639

26. Sivaranjani K, Agarkar S, Ogale S B and Gopinath C S 2012 J. Phys. Chem. C 1162581

27. Nishijima K, Kamai T, Murakami N, Tsubota $T$ and Ohno T 2008 Int. J. Photoenergy 7173943

28. Liu G, Zhao Y, Sun C, Li F, Lu G Q and Cheng H M 2008 Angew. Chem., Int. Ed. 474516

29. Perkins C L, Lee S H, Li X, Asher S E and Coutts T J 2005 J. Appl. Phys. 97034907

30. Maeda K and Domen K 2007 J. Phys. Chem. C 1117851

31. Ogisu K, Ishikawa A, Teramura K, Toda K, Hara M and Domen K 2007 Chem. Lett. 36854

32. Maeda K, Takata T, Hara M, Saito N, Inoue Y, Kobayashi H and Domen K 2005 J. Am. Chem. Soc. 127 8286 
33. Mapa M, Thushara K S, Saha B, Chakraborty P, Janet C M, Viswanath R P, Nair C M, Murty K V G and Gopinath C S 2009 Chem. Mater. 212973

34. Mapa M, Sivaranjani K, Bhange D S, Saha B, Chakraborty P, Viswanath A K and Gopinath C S 2010 Chem. Mater. 22565

35. Zhang K, Jing D, Xing C and Guo L 2007 Int. J. Hydrogen Energy 324685

36. Yu J C, Wu L, Lin J, Lia P and Li Q 2003 Chem. Commun. 131552

37. Serpone N, Borgarello E and Graetzel M J 1984 Chem. Soc. Chem. Commun. 9342

38. Amirav L and Alivisatos A P 2010 J. Phys. Chem. Lett. 11051

39. Wang D, Zhigang Z and Ye Z 2005 Chem. Mater.17 3255

40. Chai B, Peng T, Zeng P and Mao J 2011 J. Mater. Chem. 2114587

41. Chai B, Peng T, Zeng P and Zhang X 2012 Dalton Trans. 411179

42. Li Y, Guo M, Peng S, Lu G and Li S 2009 Int. J. Hydrogen Energy 345629

43. Yang H, Stephen V K, Wang Y, Gong X, Kalytchuk S, Rogach L A and Teoh W Y 2013 J. Phys. Chem. C 117 20406

44. Shah S A S, Park A R, Zhang K, Park J H and Yoo P J 2012 ACS Appl. Mater. Interfaces 43893

45. Mathew T, Sivaranjani K, Gnanakumar E S, Yamada Y, Kobayashi T and Gopinath C S 2012 J. Mater. Chem. 22 13484

46. Maity N, Rajamohanan P R, Ganapathy S, Gopinath C S, Bhaduri S and Lahiri K G 2008 J. Phys. Chem. C 1129428

47. Zhang J, Yu J, Zhang Y, Li Q and Gong J R 2011 Nano Lett. 114774

48. Bao N, Shen L, Takata T and Domen K 2008 Chem. Mater. 20110

49. Linic S, Christopher P and Ingram D B 2011 Nat. Mater. 10911

50. Warren S C and Thimsen 2012 Energy Environ. Sci. 5 5133

51. Juluri B, Lu M, Zheng Y B, Huang T J and Jensen L 2009 J. Phys. Chem. C 11318499
52. Govorov A O, Bryant G W, Zhang W, Skeini T, Lee J, Kotov N A, Slocik J M and Naik R Nano Lett. 20066 984

53. Kamat P V 2008 J. Phys. Chem. C 11218737

54. Liu Z, Hou W, Pavaskar P, Aykol M and Cronin S B 2011 Nano Lett. 111111

55. Hisatomi T, Maedo K, Takanake K, Kubota J and Domen K 2009 J. Phys. Chem. C 11321458

56. Reber J F and Meier K 1986 J Phys. Chem. 90824

57. Kongkanand A, Tvrdy K, Takechi K, Kuno M and Kamat P V 2008 J. Am. Chem. Soc. 1304007

58. Rajaambal S, Mapa M and Gopinath C S 2014 Dalton Trans. 4312546

59. Nozik A 2008 J. Chem. Phys. Lett. 4573

60. Trindade T, O'Brian P and Pickett N L 2001 Chem. Mater. 133843

61. Chen H M, Chen U K, Chang Y, Chang W S and Chen K H 2010 Angew. Chem. Int. Ed. 495966

62. Lee Y L, Fachi C and Lian S 2010 Chem. Mater. 22922

63. Hensel J, Wang G, Li Y and Zhang S Z 2010 Nano Lett. 10478

64. Yu J, Zhang J and Jaroniee M 2010 Green. Chem. 12 1611

65. Parida K M, Martha S, Das D P and Biswal N $2010 \mathrm{~J}$. Mater. Chem. 207144

66. Tsuji I, Kato H and Kudo A 2005 Angew. Chem. Int. Ed. 443565

67. Li X, Chen G, Wang Q, Wang X, Zhou A and Shen Z 2010 Adv. Funct. Mater. 203390

68. Boumaza S, Boudjemaa A, Bouguelia A, Bouarab R and Trari M 2010 Appl. Energy 872230

69. Li Q and Lu G 2008 J. Power Sources 185577

70. Pu Y, Wang G, Chang K, Ling Y, Lin Y, Fitzmorris B C, Liu C M, Lu X, Tong Y, Zhang J Z, Hsu Y J and Yat L Nano Lett. 2013133817

71. Dharani $\mathrm{P} K$, Shankar $M$ V, Murikinati $M \mathrm{~K}$, Sadanandam G, Srinivas B and Durgakumari V 2013 Chem. Commun. 499443

72. Bard A J and Fox M A 1995 Acc. Chem. Res. 28141

73. Ohtani B 2008 Chem. Lett. 373

74. Roy, K, Vinod, C P and Gopinath C S 2013 J. Phys. Chem. C 1174717

75. Roy, K and Gopinath C S 2014 Anal. Chem. 863683 